\title{
Effects of Sensitization on the Metastable Pitting Corrosion of 304 Stainless Steel
}

\author{
Yan Hou, Congqian Cheng ${ }^{*}$, Tieshan Cao, Xiaohua Min, Jie Zhao
}

School of Materials Science and Engineering, Dalian University of Technology, Dalian 116024, China *E-mail: cqcheng@dlut.edu.cn

doi: $10.20964 / 2018.07 .74$

Received: 9 April 2018 / Accepted: 23 May 2018 / Published: 5 June 2018

The effects of sensitization on the metastable pitting behaviour of 304 stainless steel in $3.5 \mathrm{wt} \% \mathrm{NaCl}$ solution were investigated via electrochemical measurements and microscopic observations. Results showed that sensitization decreased pitting potential and slightly affected metastable pitting potential. Sensitization treatment increased the nucleation frequency of metastable pitting, promoted its propagation and changed the shape of current transients. The results of scanning electron microscopy and energy-dispersive X-ray spectroscopy showed that metastable pitting was initiated at $\mathrm{MnS}$ inclusions for the solution-treated and sensitized samples. The combined effects of the passive film and inclusions were considered to play a vital role on the metastable pitting behaviour.

Keywords: stainless steel, sensitization, passive film, metastable pitting, inclusion

\section{$\underline{\text { FULL TEXT }}$}

(C) 2018 The Authors. Published by ESG (www.electrochemsci.org). This article is an open access article distributed under the terms and conditions of the Creative Commons Attribution license (http://creativecommons.org/licenses/by/4.0/). 